\title{
Sensory analysis applied to honey: state of the $\operatorname{art}^{1}$
}

\author{
Maria Lucia PIANA ${ }^{a *}$, Livia PERSANO ODDO ${ }^{\mathrm{a}}$, Antonio BENTABOL $^{\mathrm{b}}$, \\ Etienne BRUNEAU ${ }^{\mathrm{c}}$, Stefan BOGDANOV ${ }^{\mathrm{d}}$, Christine GUYOT DECLERCK $^{\mathrm{c}}$ \\ ${ }^{a}$ Istituto Sperimentale per la Zoologia Agraria, Sezione di Apicoltura, Roma, Italy \\ b Casa de la miel, Tenerife, Canarias, Spain \\ c Cari, Louvain-la-Neuve, Belgium \\ d Federal Dairy Research Station, Swiss Bee Research Centre, Liebefeld, Switzerland
}

(Received 20 February 2004; revised 11 May 2004; accepted 17 May 2004)

honey / sensory analysis / organoleptic / analytical methods

\section{INTRODUCTION}

Sensory analysis is the examination of a product through the evaluation of the attributes perceptible by the five sense organs (organoleptic attributes), such as colour, odour, taste, touch, texture and noise.

Used in many fields, sensory analysis allows to establish the organoleptic profile of diverse products (foods, cosmetics, pharmaceuticals, textiles, household products), and can be useful in knowing how they are perceived by the consumer. Until the 1960 s, sensory analysis techniques basically relied on the personal experience of expert assessors. This technique was simple and low cost, but it lacked the essential requisite of reproducibility in order to be considered a fully fledged analytical method.

In the second half of the twentieth century, new and improved sensory evaluation methods were developed using panels of assessors, well defined and controlled experimental protocols and statistical techniques for processing the results (Pangborn, 1964; Stone and Sidel,
1985; ISO 6658, 1985; SSHA and ISHA, 1990; Meilgaard et al., 1991). The advantage of these methods over traditional ones is that the results are reproducible, but the complexity and high costs limit their use to the field of research and development of new products, rather than the routine use in the framework of monitoring processes and quality control.

In the case of honey, sensory analysis was first used in France with traditional techniques, by the Gonnet team (Gonnet and Vache, 1979, 1985, 1992, 1998). In Italy, Gonnet's ideas were taken up with particular enthusiasm; much effort was dedicated to training activities and an Italian Register of Experts in the Sensory Analysis of Honey was founded, which established a standard traditional methodology including harmonized terminology, evaluation forms, tasting methods, methods for training and selecting assessors and sensory descriptions of the principal Italian unifloral honeys (Persano Oddo et al., 1995, 2000; Istituto Nazionale di Apicoltura, 1999). Similarly, Gonnet's legacy was also taken up and developed in other European countries (such as

\footnotetext{
1 This research was carried out within the national programme of the Ministero delle Politiche Agricole e Forestali (EC Regulation 1221/97).

* Corresponding author: luciapiana@libero.it
} 

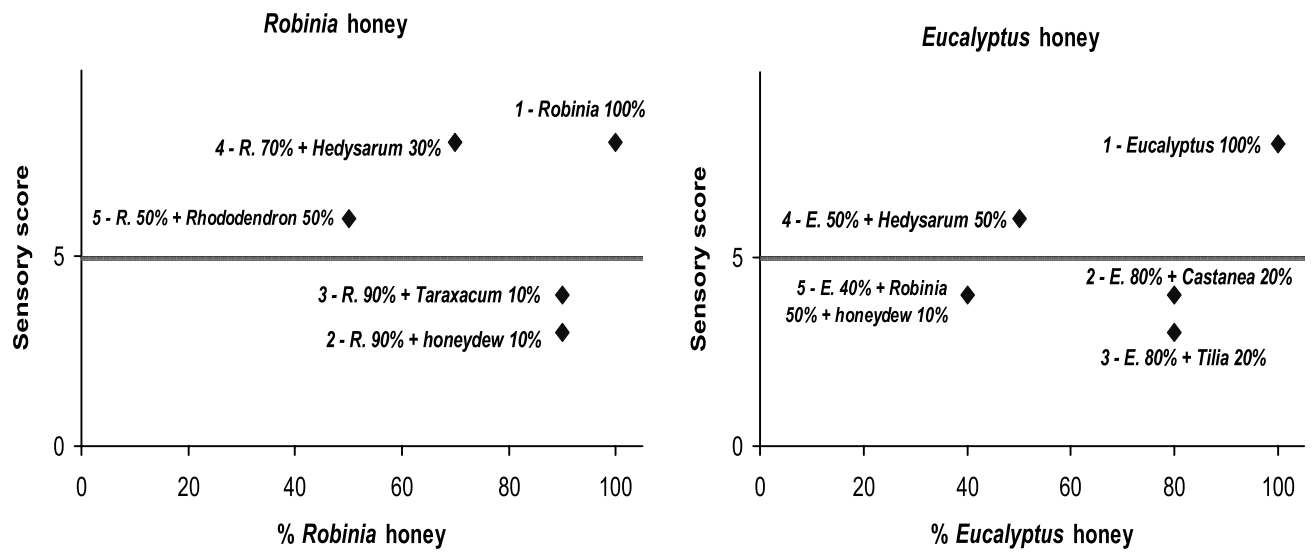

Figure 1. Classification of samples according to the percentage of unifloral honey in samples and sensory evaluation.

Spain: Serra Bonvehí and Gómez Pajuelo, 1988).

Only in recent years has there been a move to develop and apply modern techniques (Piana, 1993a, b; Bogdanov et al., 1998; Bruneau et al., 2000; Bentabol, 2002; National Honey Board, 2002a, b; Vejsnaes et al., 2003).

In 1998 a working group was set up by the International Honey Commission of Apimondia (IHC) to study the sensory analysis applied to honey (IHC, 1998, 1999, 2000, 2001a, b, 2002).

This article describes the work carried out in this field under the auspices of the IHC:

1. collection and re-organization of the large amount of information previously produced by traditional methods;

2. proposal of a harmonized routine method based on internationally recognized ISO standards for evaluating sensory defects and conformity of unifloral honeys.

\section{USE OF SENSORY ANALYSIS IN HONEY EVALUATION}

Sensory evaluation enables us to distinguish the botanical origin of honey and to identify and quantify certain defects (fermentation, impurities, off-odours and flavours). It also plays an important role in defining product standards and in the related controls, regarding botanical denominations or other specific labels. Moreover it is an essential part of consumer preference/aversion studies.

Some of the characteristics that can be revealed by sensory analysis can also be determined by laboratory analysis (for example, fermentation can be identified by testing for fermentation products or yeasts), but for other characteristics there are currently no alternative analytical methods. In particular, sensory evaluation is important in verifying the conformity of unifloral honeys, since it can reveal the presence of botanical components not picked up by other analytical systems (physicochemical and melissopalynological), but that nonetheless alter the typical sensory characteristics, sometimes to such an extent that the honey cannot be marketed as unifloral.

To illustrate this point the results of a test carried out by the Italian Register of Experts in the Sensory Analysis of Honey are reported.

Two groups of samples were set up: one comprising 5 Robinia honeys and the other one 5 Eucalyptus honeys. Only one sample in each group corresponded to a perfectly unifloral product, while the other four samples were obtained by mixing the unifloral sample with different quantities of other unifloral honeys. The samples were tested by a panel of 30 assessors who were asked to evaluate the degree of conformity by giving a score from 1 to 10 (10 being the maximum conformity and 5 the limit for marketing the honey as unifloral).

The results are reported in Figure 1: the median score awarded by the assessors for 
each sample is compared to the percentage of unifloral honey in the blend; the threshold for considering honey unifloral according to the organoleptic score (score $=5$ ) is indicated.

This example demonstrates that small quantities of a highly aromatic honey (that are usually hardly detected in blends by common laboratory analysis) can considerably alter the organoleptic characteristics of a unifloral honey (Robinia samples 2 and 3; Eucalyptus 2 and 3 ). On the contrary, much larger quantities of a delicately flavoured honey have no or little effect (Robinia 4 and 5; Eucalyptus 4). The test also confirms the importance of sensory evaluation as a basic criterion in selecting unifloral honeys for commercial purposes.

\section{HARMONIZED TERMINOLOGY AND DESCRIPTION OF EUROPEAN UNIFLORAL HONEYS}

In the study and control of unifloral honeys, sensory evaluation is commonly used to complete and interpret the overall analytical results. Therefore in the work of characterization of the principal European unifloral honeys undertaken by the IHC (Persano Oddo and Piro, 2004) it was considered indispensable to integrate the descriptions with the available sensory data.

The problem was how to tap into the large amount of knowledge accumulated by various specialists in the subject, but hardly accessible because produced with traditional methods and without any systematic standardized methodology. While aware of the limitations of a less than rigorous procedure from the point of view of modern sensory methodology, we considered it important to preserve this information collected from thousands of samples.

The first step involved compiling a uniform glossary, drawing on the experience of the authors who had worked on sensory description of honey (IHC, 2000). The harmonized glossary (reported in the online version of this paper, see appendix I) refers to all the attributes and terms used in sensory descriptions of European unifloral honeys (Persano Oddo and Piro, 2004), except odour and aroma descriptors. For these latter, the Belgian team from CARI gave a valuable contribution developing a standardized terminology. They created an "odour and aroma wheel for honey" (Bruneau et al., 2000) similar to the models previously developed for wine (Peynaud, 1980; Guinard and Noble, 1986), beer (Meilgaard et al., 1979a, b) and hard and semi-hard cheeses (Issanchou et al., 1995; Bérodier et al., 1997; Lavanchy and Bütikofer, 1999).

A key aspect of this approach is the definition of standardized terminology, based on actual references, so that the product can be consistently and unequivocally described. It should contain a sufficiently wide range of terms to describe all the possible variations in the product. While the terms are conventional and should not necessarily evoke a sensation in an untrained taster, they should do so unequivocally and with precision when two people with the same training are talking to each other. The terms are usually arranged on a wheel divided into sectors (families) and subsectors (sub-families) correspondent to one or more actual references. Experience has shown that this device can also have a positive impact on communication and product perception, in that the terms defined for technical purposes are gradually adopted by the consumers.

The first experimental honey wheel developed by the Belgian group was tried out by a small working group of IHC (IHC, 2001a) and consequently modified by adding some attributes for the differentiation of certain Mediterranean honeys. The resulting harmonized "wheel" is presented in Figure 2.

The next step was a review of the descriptive sensory data on unifloral honeys available in the literature (Persano Oddo et al., 1995, 2000; Gonnet and Vache, 1998; Bruneau et al., 2000; Sáinz Laín and Gómez Ferreras, 2000) and their integration, together with the input from the members of the IHC working group, into unified descriptions, based on the harmonized terminology.

Finally, to complete and confirm these descriptions, about 40 Italian experts took part in an experiment in which they were asked to use the harmonized terminology to describe the different unifloral honey samples.

The results of all this work are the descriptions contained in the characterization sheets of European unifloral honeys (Persano Oddo and Piro, 2004) and summarised in Table I. 


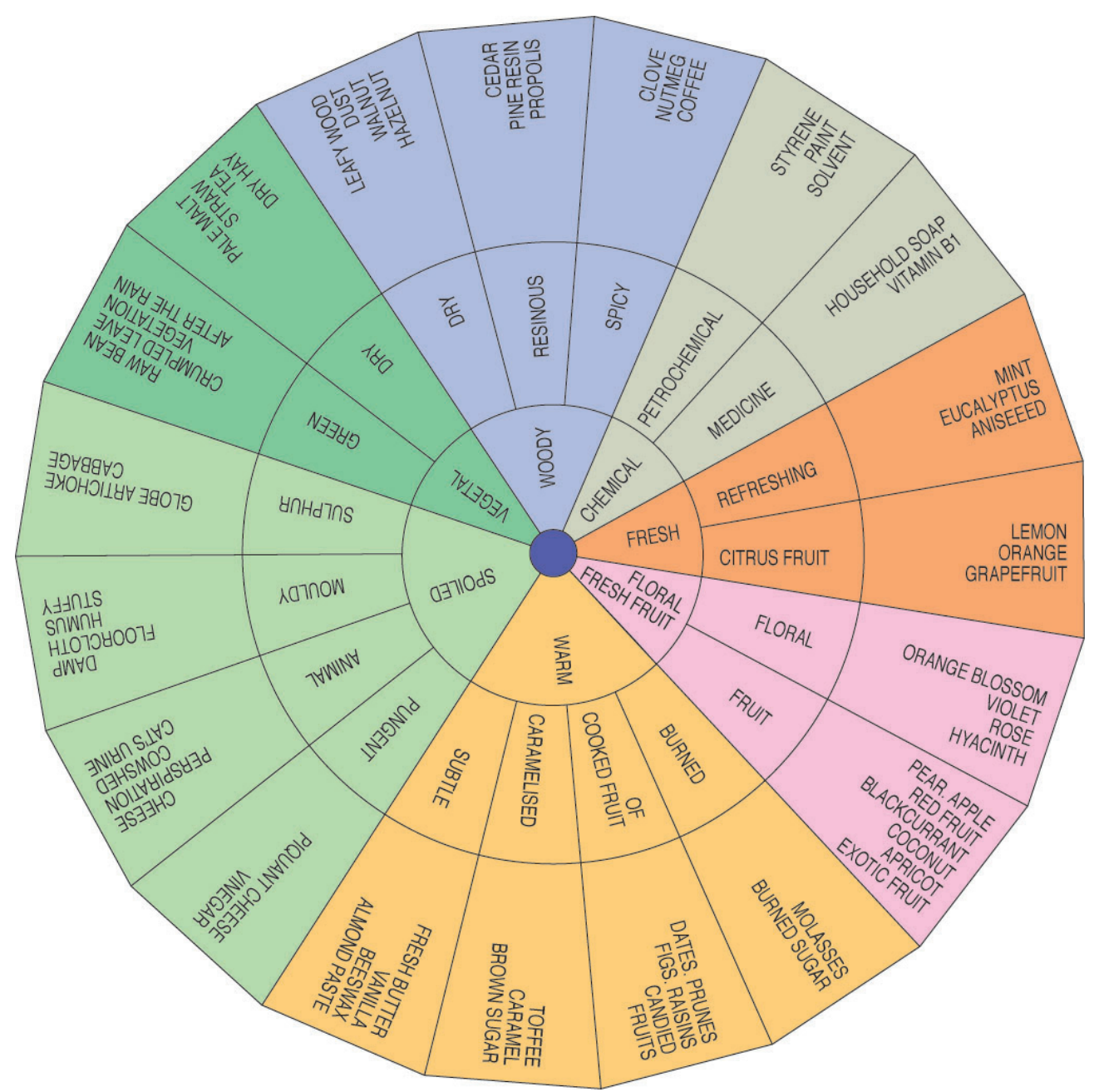

Figure 2. Odour and aroma wheel (IHC, 2001a).

\section{HARMONIZED ROUTINE METHOD FOR HONEY QUALITY EVALUATION}

In honey quality control a method for classifying or grading honey according to defects or conformity with unifloral profiles is needed. The method here proposed is the result of years of experience acquired by the laboratories that work within the IHC. It sets down the application to honey of a sensory analysis methodology for which general guidelines already exist regarding the design of test rooms (ISO 8589, 1988), general sensory analysis guidance (ISO 6658, 1985) and training of assessors (ISO 8586-1, 1993; ISO 8586-2, 1994). It is mainly based on the experience attained in the olive oil industry (International Olive Oil Council, 1996).

The aim of this method is to evaluate the olfactory-gustatory characteristics of honey. It has been designed in particular to verify the absence of defects and the conformity of the sensory profiles of unifloral honeys, referring to previously memorized standards.

Visual and tactile characteristics, while important in the overall evaluation of the product, are not included because of the need to separate the visual and tactile stage from the 
Table I. Description of main European unifloral honeys (Persano Oddo and Piro, 2004).

\begin{tabular}{|c|c|c|c|c|c|c|c|c|c|c|c|c|c|c|c|c|c|}
\hline & & & 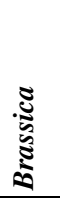 & క్̃ & 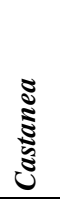 & 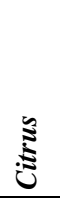 & 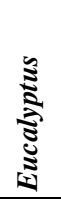 & 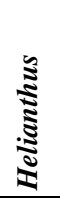 & 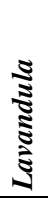 & 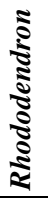 & 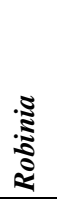 & 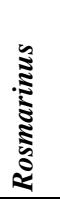 & 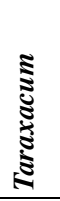 & 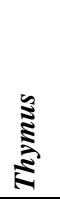 & : & 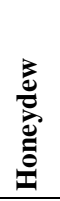 & 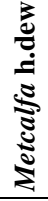 \\
\hline \multirow{3}{*}{ 㞼 } & \multicolumn{2}{|c|}{ Colour intensity (from 1 to 5 ) } & 2 & $4-5$ & $4-5$ & 1 & $3-4$ & 3 & 2 & 1 & 1 & 1 & 3 & $3-4$ & $2-3$ & $4-5$ & 5 \\
\hline & \multirow{2}{*}{$\stackrel{\tilde{\Xi}}{\oplus}$} & Normal honey colour & + & + & + & + & + & & + & + & + & + & & + & + & + & + \\
\hline & & Other tones & & + & + & & + & + & + & & & & + & & + & + & \\
\hline \multicolumn{3}{|c|}{ Intensity of odour (from 0 to 3 ) } & 2 & $2-3$ & 3 & 2 & $2-3$ & 1 & 2 & 1 & 1 & $1-2$ & 3 & 2 & 3 & 2 & 2 \\
\hline \multirow{7}{*}{\multicolumn{2}{|c|}{ 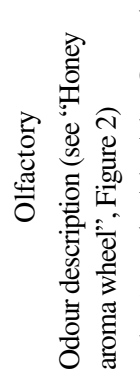 }} & Woody & & + & + & & & & + & + & & & & + & + & + & + \\
\hline & & Chemical & & & + & & & & & & & & & + & + & & \\
\hline & & Fresh & & & & & & & & & & + & & + & + & & \\
\hline & & Floral - fresh fruit & & + & & + & & + & + & + & + & + & & + & & & + \\
\hline & & Warm & & + & + & & + & + & & & + & & & & & + & + \\
\hline & & Spoiled & + & & & & + & & & & & & + & & & & \\
\hline & & Vegetal & + & & & & & + & + & & & + & & & & & + \\
\hline \multicolumn{3}{|c|}{ Sweetness (from 1 to 3 ) } & 2 & 1 & 1 & 2 & 2 & 2 & 2 & 2 & $2-3$ & 2 & 2 & 2 & 2 & 2 & 2 \\
\hline \multicolumn{3}{|c|}{ Acidity (from 0 to 3 ) } & 1 & 2 & 1 & 1 & 1 & 3 & 2 & 1 & 1 & 1 & 2 & 2 & 1 & 1 & 1 \\
\hline \multicolumn{3}{|c|}{ Bitterness (from 0 to 3 ) } & 0 & 2 & 3 & 0 & 0 & 0 & 0 & 0 & 0 & 0 & $0-1$ & 0 & $0-2$ & 0 & 0 \\
\hline \multicolumn{3}{|c|}{ Intensity of aroma (from 0 to 3 ) } & 2 & 3 & 3 & 2 & 2 & $1-2$ & 2 & 1 & 1 & $1-2$ & 3 & $2-3$ & 3 & 2 & 2 \\
\hline \multirow{7}{*}{\multicolumn{2}{|c|}{ 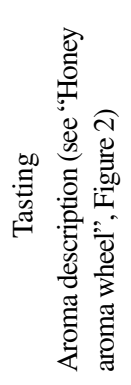 }} & Woody & & & + & & + & & + & + & & & + & + & + & + & + \\
\hline & & Chemical & & & + & & & & & & & & & + & + & & \\
\hline & & Fresh & & & & + & & & + & + & & + & & + & + & & \\
\hline & & Floral - fresh fruit & + & + & & + & & + & + & + & + & + & & + & & & + \\
\hline & & Warm & + & + & + & & + & + & + & + & + & & & & & + & + \\
\hline & & Spoiled & + & & + & & + & & & & & & + & & & & \\
\hline & & Vegetal & + & & & & & + & & & & + & & & & & + \\
\hline \multicolumn{3}{|c|}{ Persistence (from 0 to 3 ) } & 1 & 3 & 3 & $1-2$ & 2 & 1 & 2 & 1 & 1 & 1 & 3 & 2 & 3 & 2 & 2 \\
\hline \multicolumn{3}{|c|}{ After-taste } & $+/-$ & & & & & & $+1-$ & & & & & & & & \\
\hline \multirow{2}{*}{\multicolumn{2}{|c|}{$\stackrel{\bar{\Xi}}{\overline{0}}$}} & Astringency & & & + & & & & & & & & & & + & $+/-$ & $+1-$ \\
\hline & & Refreshing & $+/-$ & & & & & $+/-$ & & & & & $+/-$ & & & & \\
\hline \multicolumn{3}{|c|}{ Crystallisation rate (from 1 to 3 ) } & 3 & 2 & 1 & 2 & 2 & 3 & 2 & 2 & 1 & 2 & 3 & 2 & 2 & 1 & 1 \\
\hline \multicolumn{3}{|c|}{ Other physical characteristics } & + & + & + & & & + & & & & & + & & & + & + \\
\hline
\end{tabular}

olfactory-gustatory stage, as there is much evidence for the direct influence of the former on the results of the latter. Moreover, in the evaluation of unifloral honeys, some visual and tactile characteristics (physical state, consistency, crystals) are not strictly dependent on the origin of the product, since they are also influenced by the processing methods. Finally, 
some attributes, such as colour, can be estimated using instrumental analysis.

\subsection{Principle}

The method is based on the evaluation of the olfactory-gustatory characteristics of honey by assessors trained to identify sensory stimuli on the basis of previously memorized standards (ISO 8586-1, 1993; ISO 8586-2, 1994) and to quantify them on an unstructured scale of $10 \mathrm{~cm}$ (ISO 4121, 1987). The evaluation is carried out according to the conditions and general methodology set down in ISO 6658 (1985).

\subsection{Test room}

The room where the sensory analyses are carried out must conform to ISO 8589 (1988), at least as regards the minimum requirements (lighting, temperature, noise, odours). Individual booths should be set up, so that the assessors can work on their own without distraction (modular mobile units can be used).

\subsection{Setting up the panel: selection and training}

A panel consists of a minimum of 7 assessors. ISO 8586 standard should be followed for selection and training of assessors. The assessors must have memorized the characteristics they have to evaluate in their long-term memory. There should also be a panel leader responsible for coordinating the trials and collecting and processing the results. The panel leader also oversees the selection, training and monitoring of the performance of the members of the panel.

\subsection{Preparation of sample}

\subsubsection{Sampling beakers}

The beakers or containers used to present the samples to the assessors should meet the following requirements:

- enable the samples to be presented in a homogeneous and anonymous way (identical containers with no distinguishing marks apart from the identification code);

- be odourless;
- mask the colour of the honey (coloured or opaque non-white containers; alternatively coloured light can be used (e.g. red) with white containers);

- help the liberation and concentration of the honey odours retarding their dispersion (for instance by having a covering lid).

Oil sampling beakers defined in the COI/ T.20/Doc. No. 5 norm (International Olive Oil Council, 1987) meet these requirements. In some tests $30 \mathrm{ml}$ red plastic beakers with tight covers (N. 4196, www.semadeni.com) were used.

\subsubsection{Preparation of sample}

Samples can be prepared in two different ways.

\subsubsection{Crude sample}

This preparation should be used for evaluating the olfactory-gustatory characteristics in the way in which they are perceived by the consumer. The samples are prepared as follows: each sample is given a random three-figure code; about $30-40 \mathrm{~g}$ of the sample are put into the sampling beaker (one for each assessor), which is then covered with a suitable lid (e.g. petri dish, aluminium foil, cling film). The honey should be transferred in such a way as to minimize any alteration due to manipulation and to ensure that the sub-samples look the same. To guarantee anonymity, the technician preparing the samples for testing should not perform the sensory analysis. The sample temperature must be between 18 and $25^{\circ} \mathrm{C}$. The evaluation should take place within $24 \mathrm{~h}$ after sample preparation. If honey is covered with a tight lid, samples can be evaluated within a longer period of time. The $30-40 \mathrm{~g}$ quantity is recommended for a testing beaker with a total capacity of about $130 \mathrm{ml}$. Containers of different dimensions can be used, maintaining the sample/volume ratio near $1 / 4-1 / 5$, with a minimum of $10 \mathrm{~g}$ of honey per assessor.

\subsubsection{Preparation of dilute sample}

Samples should be diluted when it is felt that interference from secondary characteristics (physical state and type of crystallization, water content) may negatively affect the 
reproducibility of the method. Dilution is particularly advisable in evaluating olfactory characteristics and in evaluating conformity with a botanical profile. The samples are prepared as follows: a portion of the sample is diluted with odourless water (distilled or low in mineral content) in proportions of 1 part water to 5 parts honey (in weight), so that the final water content of the mixture is about $30 \%$. The mixture is homogenized; if some crystallized parts are still present it is possible to heat the solution in a closed container in a water bath at $40{ }^{\circ} \mathrm{C}$ until sugar crystals are completely dissolved. The sample is then divided up among the test beakers and the same procedure followed as described in Section 4.4.2.1.

\subsection{Evaluation}

\subsubsection{General conditions}

Assessors must abstain from smoking, eating and drinking anything except water for $30 \mathrm{~min}$ before the evaluation. They should also refrain from using toothpaste or highly aromatic mouthwashes, perfumed toiletries and anything else that may give rise to odours of any kind being introduced into the tasting room.

Each assessor has the material necessary for sensory analysis and evaluation forms (see appendix II in the online version of this paper). The assessors work individually filling in the form that will be handed in by the panel leader.

The number of samples per session should be limited to a maximum of 7 . Between to sessions at least $30 \mathrm{~min}$ have to pass and assessors must be rested. The sessions should be timed to take place at least $2 \mathrm{~h}$ after main meals. The best sensitivity is obtained in the middle hours of the morning and afternoon. The order in which the samples are presented to the assessors should vary.

\subsubsection{Evaluation of the olfactory characteristics}

The olfactory characteristics are evaluated at first. In the case of crude samples of honey, the odour is evaluated immediately after the honey has been spread on the surface of the beaker with the plastic spoon, to encourage the liberation of volatile substances and to produce an evaporation surface area that is the same for all samples. In the case of dilute samples, it is sufficient to swirl the sample round in the beaker to encourage evaporation. The panellist has to breath in for some seconds over the top of the beaker. The odour has to be evaluated both immediately after having spread or swirled the honey and after 10 or $20 \mathrm{~s}$. Before taking a second sniff, the panellist has to wait for 5-20 s, or even longer, so that the full force of the odour is perceived. The intensity of any defect perceived and, if required, conformity with the unifloral profile are immediately noted on the form.

\subsubsection{Evaluation of the olfactory- gustatory characteristics (tasting)}

To evaluate mouth sensations a small quantity ( 1 or $2 \mathrm{~g}$ ) of honey is sampled with a disposable (or stainless steel) spoon. The honey is allowed to dissolve in the mouth before being slowly swallowed, so that the taste (sweet, salty, acid, bitter), the aroma (intensity and quality), the persistence, any after-taste and other mouth sensations can be perceived.

When the honey is presented as is, the panellist should concentrate on the chemical aspects of the mouth sensations and should not be distracted by tactile characteristics. At least 1 or 2 min should be allowed to lapse before a second tasting, much longer in the case of persistent honeys, to give the taste buds time to recover before tasting again, in order to detect details that may not have been detected the first time. The evaluation takes into consideration many descriptors that are summarized by the assessor into a single evaluation regarding the intensity of each defect identified and, when required, conformity with the unifloral profile. Between samples, the panellist has to wait for a few minutes and eat a piece of apple (preferably juicy and slightly acidulous but not bitter or astringent) or low-in-salt bread. Alternatively the panellist has to rinse his mouth with water or rose-hip tea.

\subsubsection{Evaluation of defects and unifloral profiles}

\subsubsection{Defects}

Defects evaluation is based on the identification of the correspondent reference standard, previously memorized by assessors, and 
on the quantification of the intensity, compared with the references, on an unstructured 10-centimetre scale. Reference samples are prepared specifically for this purpose. Off-odour and off-flavour of fermentation and foreign tastes and odours (such as smoke and thymol taints) are considered as defects.

\subsubsection{Unifloral profiles}

Evaluation of unifloral conformity is carried out by a panel of specialized expert assessors who have been trained to recognize the different unifloral types, having memorized their typical characteristics as well as every possible variation of the product. During this evaluation the assessor must interpret a complex profile comprising various components that may vary independently of each other. So the task is not to evaluate the intensity of a memorized sensation, but rather to give an overall assessment that takes into consideration all the components perceived, and to quantify them on the unstructured 10-centimetre scale in comparison with memorized reference samples. The criterion for selecting reference samples should be their perfect conformity with the physicochemical and melissopalynological characteristics (Persano Oddo and Piro, 2004; this paper also reports the sensory characteristics of the principal unifloral honeys).

\subsubsection{Evaluation form}

The assessors note the score for each descriptor on an evaluation form (see appendix II in the online version of this paper).

\subsection{Processing and interpreting the results}

When the assessors have completed their evaluations, the panel leader collects the results (measuring in centimetres the distance between the left extreme of the scale and the sign put by the assessor) and proceeds to calculate the following statistical indices: median $(\mathrm{M})$, and robust standard deviation $(\mathrm{S})$ :

$$
\mathrm{S}=\frac{1.25 \cdot \mathrm{IQR}}{1.35 \cdot \sqrt{\mathrm{N}}}
$$

where:

$\mathrm{N}$ is the the number of responses.
IQR is the the interquartile range, that is the spread between the 75 th and 25 th percentile (=75th percentile -25 th percentile).

The median values are used to classify the samples according to the presence of sensory defects and conformity in the case of uniflorals. Robust standard deviation is an index of the reliability of the test. Only results for which the value of this parameter is equal to, or lower than, 1 should be taken into consideration. Appendix III in the online version reports an example of the use of this type of results (Bentabol, unpublished data).

\subsection{The "yes/no" classification method}

A very simple yes/no classification system (ISO 6658, 1985) is used in some laboratories of the IHC group and may represent an alternative to the routine method. In this case the distribution of the results can be evaluated by means of a simple $\chi^{2}$ test (at a level of confidence of 95\%): results are valid if there is, in one category (yes or no), a given number of replies, depending on the number of assessors (Appendix IV in the online version).

An intrinsic drawback of the yes/no method is the difficulty of defining with precision the limit between the two categories (accepted/not accepted) by means of reference samples. In fact this would imply a previous decision of which level of defects (or uniflorality) is acceptable or not: for evaluation of defects, reference samples with a low level of a defect could be perceived or not by the assessors; on the other hand, for evaluation of uniflorality, border line reference samples may be very different to each other. Therefore, when definitely good or bad samples are tested, results are generally valid, but when intermediate samples are assessed it is very difficult to obtain valid results, because assessors perceive or interpret them in different ways.

With the proposed harmonized routine quantitative method, the use of a grading system allows training of the panel with very typical reference samples (near to the right extreme of the scale) and shifts the problem of the acceptability of the samples to the numeric results (see Sect. 4.8). 


\subsection{Results of some preliminary tests with the harmonized routine method}

Some preliminary tests were carried out to verify the suitability of the proposed routine method (quantitative method) and to compare it with the yes/no method.

In a first trial 10 samples were tested for 3 characteristics: uniflorality, fermentation and smoke taint. Three panels of 8 to 16 assessors each were asked to evaluate the samples according to the harmonized routine method described above and to classify them according to the yes/no classification system (correspondence/not correspondence to the unifloral profile and presence/absence of the 2 defects).

Results were elaborated separately for the 3 panels (in total 90 answers: 10 honeys $\times 3$ characteristics $\times 3$ panels) and all together (as a whole big panel: in total 30 answers: 10 honeys $\times 3$ characteristics $\times 1$ panel).

The validity of results was evaluated through the robust standard deviation (not higher than 1) for the quantitative routine method, and through the $\chi^{2}$ test (see appendix IV in the online version) for the yes/no method.

When the answers of the 3 panels were elaborated separately, the valid results were 75 out of $90(83 \%)$ with the quantitative routine method, and 62 out of $90(69 \%)$ with the yes/ no method.

When answers were elaborated altogether, all results were valid with the quantitative routine method, while with the yes/no method 7 out of $30(23 \%)$ remain not valid.

A second series of trials was performed in order to obtain more information on the repeatability of the harmonized routine method. Two series of unifloral honeys of different purity were prepared: series $\mathrm{A}=4$ chestnut honeys and series $\mathrm{B}=4$ Robinia honeys. The two series were presented (anonymously and randomly) to two groups of 12 assessors: series A - chestnut, to panel A and series B - Robinia to panel B. Assessors were asked to evaluate the uniflorality of the samples. In the afternoon of the same day the same samples were presented a second time for the evaluation to the same assessors, always anonymously and randomly.

The results of the two consecutive evaluations were processed both separately (12 responses) and together (24 responses). Median and confidence intervals at $95 \%$ were calculated and results were considered valid if the robust standard deviation was not higher than 1 .

Results are presented in Figure 3: the full elaboration ( 24 answers) is identified with the codes 1,0, 2,0, 3,0 etc.; the two repetitions (12 answers each) are identified with the codes 1,1, 2,1, 3,1, etc., and 1,2, 2,2, 3,2 etc. Invalid results are highlighted in grey (Castanea 2,2 and Robinia 4,1).

A greater degree of dispersion among the results were recorded for samples with intermediate characteristics, whose correspondence was interpreted and quantified less uniformly by the assessors (perhaps because they had not received enough training in the use of the unstructured scale). For one sample (Robinia sample 4) the 2 repetitions gave not comparable results, but one of the 2 repetitions (4.1) also resulted not valid.

Samples were later presented for a third time to the same assessors, who were asked to perform a simple yes-no classification. In this case results related to Robinia sample 2 and 4 were not valid (Fig. 4).

These results confirm the suitability of the proposed routine method for the evaluation of honey defects and uniflorality, the main problem being the organization of a numerous and skilled panel (in our trials we considered insufficient training as the main cause of some unsatisfactory results).

The yes/no system can have a useful application as a screening method, but for problematic samples (with intermediate characteristics) the quantitative routine method is recommended even if more training and, sometimes, more replies are needed to get valid results.

\section{CONCLUSIONS}

The traditional sensory evaluation of honey, widely used throughout the honey-producing world, has proved an important instrument for quality control and improvement of honey quality.

Nevertheless, the use of sensory analysis in the fields of science and quality control necessarily demands a shift to modern, more reliable and reproducible techniques, even if their application to honey requires what might seem 
(A) Castanea

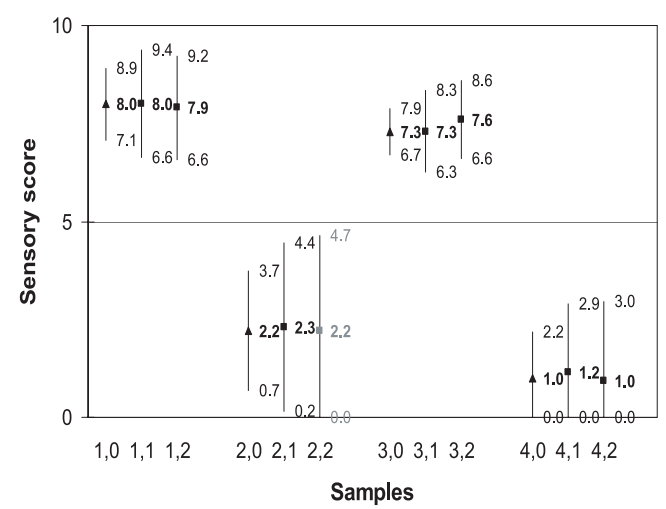

(B) Robinia

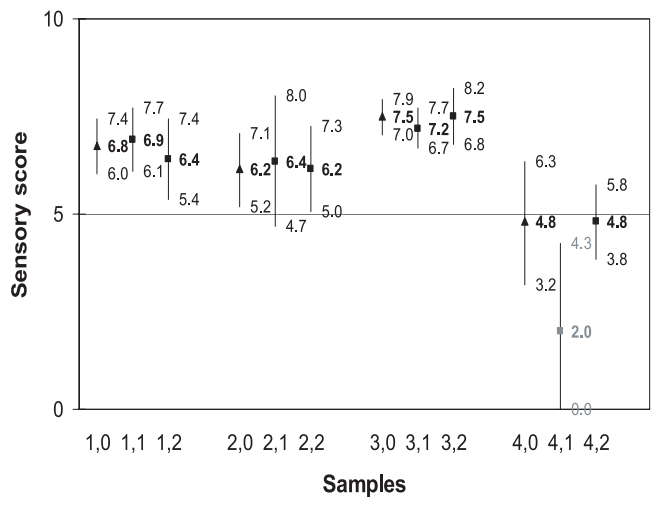

Figure 3. Results of the repeatability trials carried out with the harmonized routine method. In A the results of the 2 evaluations carried out by the panel A on the 4 Castanea samples (expressed as median and confidence intervals at $95 \%$ ) are reported and compared with the same results processed all together. In B the results of the panel $\mathrm{B}$ on the 4 Robinia samples are reported. 1,0 = sample \#1 both evaluations elaborated together; 1,1 = sample \#1 first evaluation; 1,2 = sample \#1 second evaluation; 2,0 = sample \#2 both evaluations, etc. For Castanea sample \#2 second evaluation and for Robinia sample \#4 first evaluation the results have a robust standard deviation $>1$ and are not valid. The two repetitions of Robinia sample \#4 gave different results.
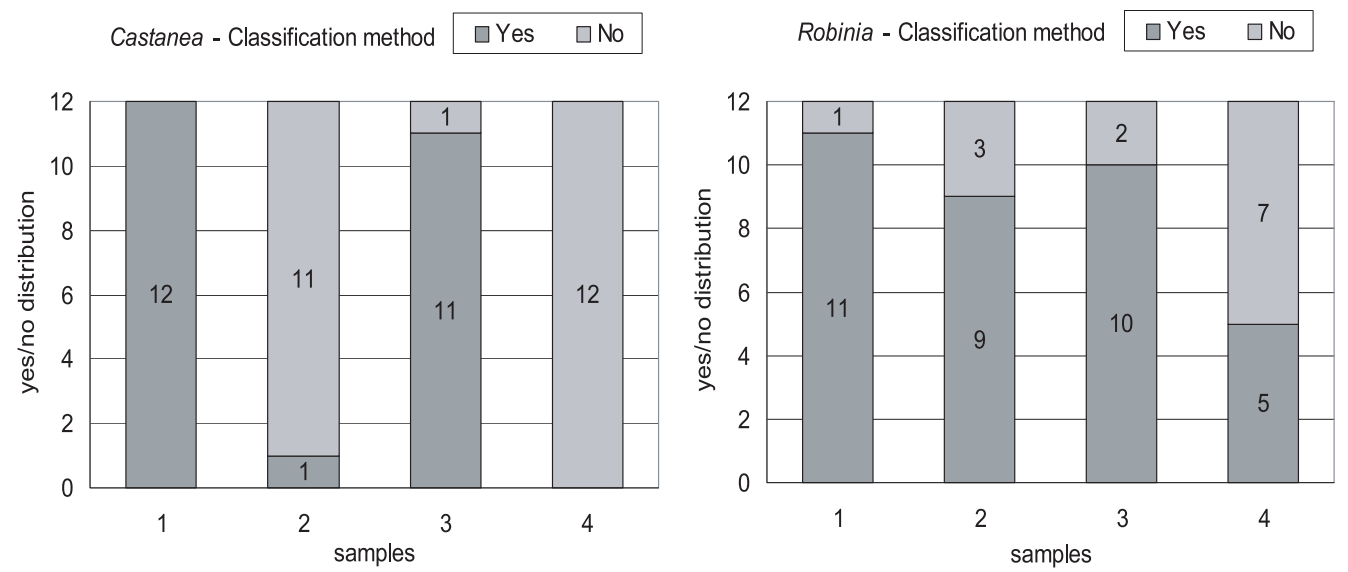

Figure 4. Results of the yes/no evaluations. In the histograms the number of the answers in each category is indicated. Results of Robinia samples \#2 and \#4 are not valid (with 12 assessors at least 10 replies in the same category are needed, see Appendix IV in the online version).

to be a disproportionate effort in comparison with the economic value of the product.

The procedures described above go some way towards meeting the urgent need for a standardized method, albeit with a lower degree of reproducibility, taking into account the objective fact that at the present time, most of the assessors are trained as "experts" and are all involved to a some extent in apiculture and honey production.

Some variability factors in the evaluation of unifloral honeys could be avoided by using a "profile method" (as defined in ISO 6564, 1985). While the routine method only requires an overall assessment that takes into consideration all the components perceived (and 
quantifies them on the unstructured 10-centimetre scale in comparison with memorized reference samples), the profile method would imply selecting, for each unifloral honey type, the most significant attributes, with the respective reference standards, and to use them to draw a complete reference profile.

Work on the development of these modern techniques to describe the sensory profile of honey and evaluate conformity with specific sensory requirements has barely started but seems promising.

It is important that in fields where modern techniques cannot be applied because they are economically unviable, traditional methods continue to be used so that the experience and results gained in around 25 years of activity are not lost.

It is also important that works in the two branches of sensory analysis of honey continue to progress in tandem, thus enabling the traditional branch to progress and improve and the modern one to be receptive to the changes and needs of honey producers.

\section{REFERENCES}

Bentabol A. (2002) Aportaciones metodológicas al análisis sensorial descriptivo de las mieles. Descripción de olores y aromas, Alimentaria 339, 49-52.

Bérodier F., Lavanchy P., Zannoni M., Casals J., Herrero L., Adamo C. (1997) Guida per la valutazione olfattogustativa dei formaggi a pasta dura e semidura, G.E.CO.TE.F.T., Poligny, France.

Bogdanov S., Kilchenmann V., Fluri P., Bühler U., Lavanchy P. (1998) Influence of organic acids and components of essential oils on honey taste, Am. Bee J. 1, 61-63.

Bruneau E., Barbier E., Gallez L.M., Guyot-Declerck C. (2000) La roue des arômes des miels, Abeilles \& Cie 77, 16-23.

Gonnet M., Vache G. (1979) Technique de dégustation des miels et recherche d'un système de notation et de classification objectif pour apprécier leur qualité par l'analyse sensorielle, 27th Apimondia Int. Apic. Congr., Athènes, pp. 499-506.

Gonnet M., Vache G. (1985) Le goût du miel, Ed. U.N.A.F., Paris, France.

Gonnet M., Vache G. (1992) The taste of honey, Apimondia, Bucarest.

Gonnet M., Vache G. (1998) Analyse sensorielle descriptive de quelques miels monofloraux de France et d'Europe, Ed. Abeille de France, Paris, France.
Guinard J.X., Noble A.C. (1986) Proposition d'une terminologie pour une description analytique de l'arôme des vins, Sci. Aliment. 6, 657-662.

International Honey Commission (IHC), Minutes of the IHC meetings: Toledo (1998), Dijon (1999), Celle (2000) Louvain-la-Neuve (2001a), Atene (2001b), Celle (2002). Online at: http:// www.apis.admin.ch/host/honey/minutes.htm (accessed on 12 August 2004).

International Olive Oil Council (1987) Sensory analysis of olive oil. Standard. Glass for oil tasting. COI/T.20/Doc. No. 5, online at: http://www.internationaloliveoil.org/downloads/orga2.pdf (accessed on 14 June 2004).

International Olive Oil Council (1996) Sensory analysis of olive oil. Method. Organoleptic assessment of virgin olive oil. COI/T.20/Doc. No. 15/Rev. 1, online at: http://www.internationaloliveoil.org/ downloads/orga6.pdf (accessed on 14 June 2004).

ISO 6658 (1985) Sensory analysis - Methodology General guidance, International Organization for Standardization, Geneva (http://www.iso.org).

ISO 6564 (1985) Sensory analysis - Methodology Flavour profile methods, International Organization for Standardization, Geneva (http://www. iso.org).

ISO 4121 (1987) Sensory analysis - Methodology Evaluation of food product by methods using scales, International Organization for Standardization, Geneva (http://www.iso.org).

ISO 8589 (1988) Sensory analysis - General guidance for the design of test rooms, International Organization for Standardization, Geneva (http://www. iso.org)

ISO 5492 (1992) Sensory analysis - Vocabulary, International Organization for Standardization, Geneva (http://www.iso.org).

ISO 8586-1 (1993) Sensory analysis - General guidance for the selection, training and monitoring of assessors - Part 1: Selected assessors, International Organization for Standardization, Geneva (http://www.iso.org).

ISO 8586-2 (1994) Sensory analysis - General guidance for the selection, training and monitoring of assessors - Part 2: Experts, International Organization for Standardization, Geneva (http://www.iso.org).

Issanchou S., Lesschaeve I., Koster E.P. (1995) Screening individual ability to perform descriptive analysis of food products: basic statements and application to a Camembert cheese descriptive panel, J. Sens. Stud. 10, 349-368.

Istituto Nazionale di Apicoltura (1999) Albo nazionale degli allevatori di api regine. Albo nazionale degli esperti in analisi sensoriale del miele. Albo nazionale degli esperti in melissopalinologia, Istituto Nazionale di Apicoltura, Bologna.

Lavanchy P., Bütikofer U. (1999) Caractérisation sensorielle de fromages à pâte dure ou mi-dure fabriqués en Suisse, Mitt. Lebensm. Hyg. 90, 670683. 
Meilgaard M.C., Dalgliesh C.E., Clapperton J.F. (1979a) Terminologie de flaveur de la bière, Bios $10,2$.

Meilgaard M.C., Reid D.S., Wuborski K.A. (1979b) Reference standards for beer flavour terminology system, J. Am. Soc. Brew. Chem. 40, 119-128.

Meilgaard M., Civille G.V., Carr B.T. (1991) Sensory Evaluation Techniques, CRC Press, Boca Raton.

National Honey Board (2002a) Carbohydrates and sweetness of honey, Technical information and applications for honey, National honey board, http://www.nhb.org/download/factsht/4tastes.pdf (accessed on 14 June 2004).

National Honey Board (2002b) Sensory attributes of honey, Technical information and applications for honey, National honey board, http://www.nhb.org/download/factsht/sensory.pdf (accessed on 14 June 2004).

Pangborn R.M. (1964) Sensory evaluation of food: a look backward and foreward, Food Technol. 18, 1309.

Persano Oddo L., Piro R. (2004) Main European unifloral honeys: descriptive sheets, Apidologie 35 (Suppl. 1), S38-S81.

Persano Oddo L., Piana L., Sabatini A.G. (1995) Conoscere il miele. Guida all'analisi sensoriale, Avenue Media, Bologna, Italia.

Persano Oddo L., Sabatini A.G., Accorti M., Colombo R., Marcazzan G.L., Piana M.L., Piazza M.G.,
Pulcini P. (2000) I mieli uniflorali - Nuove schede di caratterizzazione, Ministero delle politiche Agricole e Forestali, Roma.

Peynaud E. (1980) Le goût du vin, Dunod Ed., Paris.

Piana M.L. (1993a) Aromi del miele: gli assaggiatori in grado di rilevarli, Apitalia 20, 22-25.

Piana M.L. (1993b) Contenuto in acqua e cristallizzazione variano l'intensità dell'odore del miele, Apitalia 20, 20-23.

Sáinz Laín C., Gómez Ferreras C. (2000) Mieles españolas. Características e identificación mediante el análisis del pollen, Ed. Mundi-Prensa, Madrid.

Serra Bonvehí J., Gómez Pajuelo A. (1988) La calificación de mieles mediante el análisis organoléptico, Apiacta 23, 103-108.

SSHA (Societé Scientifique d'Hygiène Alimentaire), ISHA (Institut Scientifique d'Hygiène Alimentaire) (Eds.) (1990) Évaluation sensorielle. Manuel méthodologique, Lavoisier, Paris.

Stone H., Sidel J.L. (1985) Sensory evaluation practices, Academic Press, San Diego.

Vejsnaes F., Theuerkauf R., Wienberg L. (2003) The practical application of sensory analyses in the evaluation of honeys, 38th Apimondia Int. Apic. Congr., Ljubljana, CD Rom, Book of Abstract, pp. 784-785. 